\title{
The Influence of the Psychological Distance between Family Members on Personality Formation
}

\author{
Fumihiro Omasu1*, Yuuki Ogawa², Yuka Sugiura², Mami Hamamoto² \\ ${ }^{1}$ Department of Health and Nutrition, Faculty of Health and Nutrition, Yamagata Prefectural Yonezawa University of Nutrition Sciences, \\ Yonezawa-shi, Japan \\ ${ }^{2}$ Department of School Health, Faculty of Education, Kumamoto University, Kumamoto-shi, Japan \\ Email: *omasu@yone.ac.jp
}

How to cite this paper: Omasu, F., Ogawa, Y., Sugiura, Y. and Hamamoto, M. (2016) The Influence of the Psychological Distance between Family Members on Personality Formation. Open Journal of Preventive Medicine, 6, 222-232.

http://dx.doi.org/10.4236/ojpm.2016.610021

Received: September 30, 2016

Accepted: October 15, 2016

Published: October 18, 2016

Copyright $\odot 2016$ by authors and Scientific Research Publishing Inc. This work is licensed under the Creative Commons Attribution International License (CC BY 4.0).

http://creativecommons.org/licenses/by/4.0/

(c) (i) Open Access

\section{Abstract}

The purpose of this study was to examine the relationship between the family relationships recognized by children and mental health after becoming adults, with emphasis on the forms of recognition from the viewpoint of children. It consisted of an anonymous questionnaire survey using a multiple-choice and fill-in-the-answer format among 451 university students as the subjects. The questionnaire included an investigation into the gender, family relationship from the higher grades of elementary school to secondary school, self-esteem, self-efficacy, and the tendency towards depression and anxiety of the subjects. The results of this study suggested that the more balanced the psychological distance between family members, the lower the score showing a tendency towards anxiety, and vice versa. The results also suggested that the more balanced the psychological distance between family members, the lower the score showing a tendency towards depression, and vice versa. Therefore, it is assumed that the balance of the psychological distance between each member has a stronger impact on the tendency towards anxiety and depression than the length of the psychological distance. In terms of gender, there were no differences in selfesteem, self-efficacy, or the tendency of depression and anxiety. In conclusion, this study partially revealed how the family relationships recognized by children impact personality formation in the process of becoming adults.

\section{Keywords}

Psychological Distance, Self-Esteem, Self-Efficacy, Depression, Anxiety 


\section{Introduction}

Issues regarding the mental health of children at school are a matter of social concern. One issue is truancy, which is believed to be due to mental instability such as an increased tendency towards anxiety or depression and a lack of self-esteem and selfefficacy [1]-[4]. As a result, this may lead to emotional instability with uncontrolled emotions as well as heavily poor academic performance or learning disabilities.

It is not difficult to imagine that the family plays a vital role in the physical and mental health of children. In particular, the family significantly impacts the mental health of children during infancy and childhood when children heavily depend on their parents both physically and mentally. The stable state of a family is connected to the emotional stability of children. In addition, children develop a base for their social skills through communication with their family along with their ability to adapt to interpersonal relationships, which may potentially lead to depression and anxiety. Moreover, it has been demonstrated that the self-esteem of children can be enhanced to improve their depressive state by having the parents talk to their children and praise them at an appropriate time [3] [4].

This is the first study focusing on family relationships recognized from the viewpoint of children. Accordingly, the purpose of this study is to examine the relationship between the family relationships recognized by children and mental health after becoming adults, with emphasis on the forms of recognition from the viewpoint of children. Furthermore, university students were used as the subjects of the investigation in order to prevent an unsettled state of body or mind, which is unique to adolescents, from impacting the research study.

\section{Methods}

A questionnaire survey was conducted among 451 university students as the subjects (male 211, female 240). The range in age was 19 to 24 , with an average age of $20.3 \pm 1.8$ years (mean \pm standard deviation). Students with a history of treatment or therapy that might have influenced their psychological health, and single parent students, namely those students with only a mother or a father were excluded.

In the survey, questionnaire sheets were distributed right after classes and collected immediately once completed by the students. Incomplete answers within the collected questionnaire sheets were excluded.

The survey in this study was an anonymous questionnaire survey in a multiplechoice and fill-in-the-answer format with the cooperation of the students. The questionnaire included an investigation into the gender, family relationships from the higher grades of elementary school to secondary school, self-esteem, self-efficacy, and the tendency towards depression and anxiety of the subjects.

Regarding the family relationships from the higher grades of elementary school to secondary school, the students were asked to imagine a time when family members were all together and express the psychological distance among family members using 
the method of "Figures of Family Relationships." The method of the "Figures of Family Relationships" is a "Schematic Projective Technique (SPT)," and a projective technique of images that expresses real and ideal family relationships (structure and dynamics of a family), by writing circles the size of a one-yen coin representing the components of a family, on a paper with a circle (representing the frame of a family) having a diameter of $12 \mathrm{~cm}$ drawn thereon [5] [6]. Based on the categorization of family patterns in the previous study [7], we categorized them into patterns including a pattern with equal and close distances among the three members, a pattern with equal and intermediate distances among the three members, a pattern with a close distance between father and child, a pattern with a close distance between mother and child, and a pattern with a close distance between mother and father. Taking into consideration other family patterns, this study additionally included a pattern with equal and long distances among the three members, a pattern with equal distances between two members (with a long distance between father and child), a pattern with equal distances between two members (with a long distance between mother and child), and a pattern with equal distances between two members (with a long distance between mother and father). In so doing, aspects of the mentality of family members were understood visually and as an image [8]. In addition, the distances among the three members (between father and child/between mother and child/between father and mother) were also measured via a method in combination with previous studies [7] [8] (Figure 1). Since the number of applicable subjects was small, the scores of each item regarding mental health in the three patterns with equal distances between two members were aggregated for analysis.

In the survey regarding the degree of self-esteem, we employed a modified survey method of the previous studies [1] [3] [4]. This survey consisted of eight items based on the free description of university or college students but not from the viewpoint of researchers. The close relationship with mental health was also identified.

In the survey regarding the degree of self-efficacy, we employed a modified survey method of the previous studies [2] [9]. It involved a questionnaire sheet to measure the degree of personal and general recognition of self-efficacy. It consisted of 11 items, with each item making up 4 points.

In the survey on depression, we employed the DSRS-C (Depression Self-Rating Scale for Children) which consists of 18 items and was created by Birleson et al. [10] [11] for the purpose of screening the depressive state of children. The state of the most recent one week was evaluated based on three levels. Based on the answers, a score of zero, one, or two points was assigned, with the full score set at 36 and the cut-off score set at 16.

In the survey on the tendency towards anxiety, we employed the SAS (Selfrating Anxiety Scale) invented by Zung [12]. This is a simple questionnaire sheet consisting of only 20 questions and an investigation as a mental self-assessment that evaluates the degree and characteristics of one's own anxiety symptoms. Due to its high reliability and validity, it is useful in the self-evaluation of the current mentality of those suffering from anxiety. 


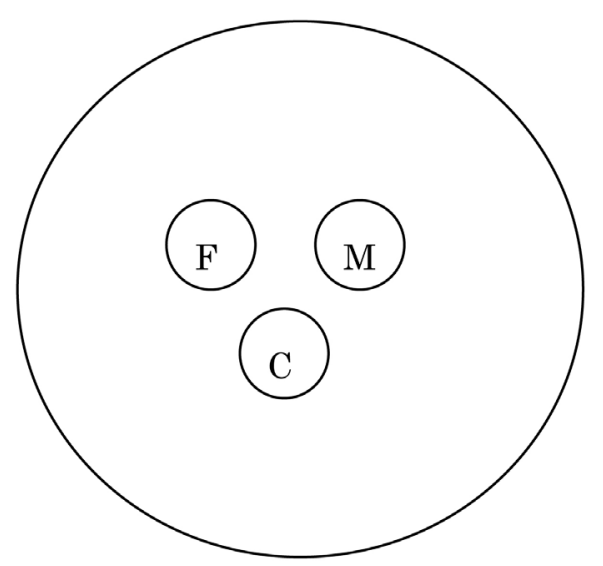

Pattern with equal and close distances among the three members

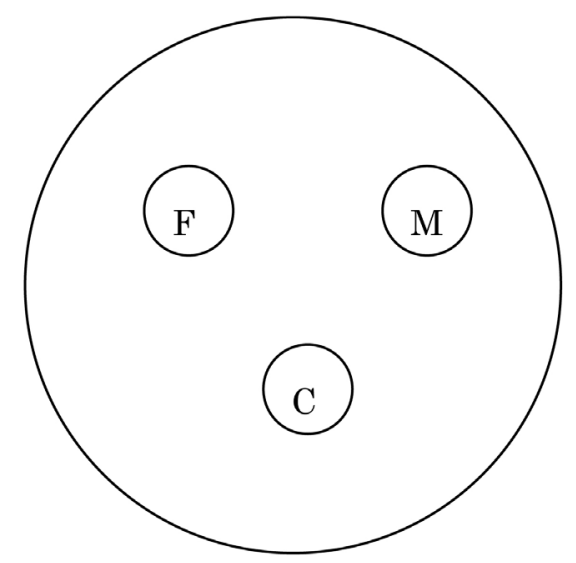

Pattern with equal and intermediate distances among the three members

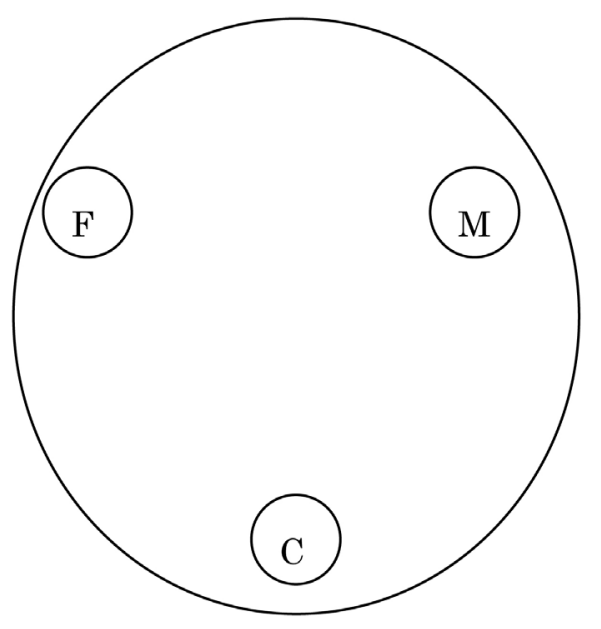

Pattern with equal and long distances among the three members

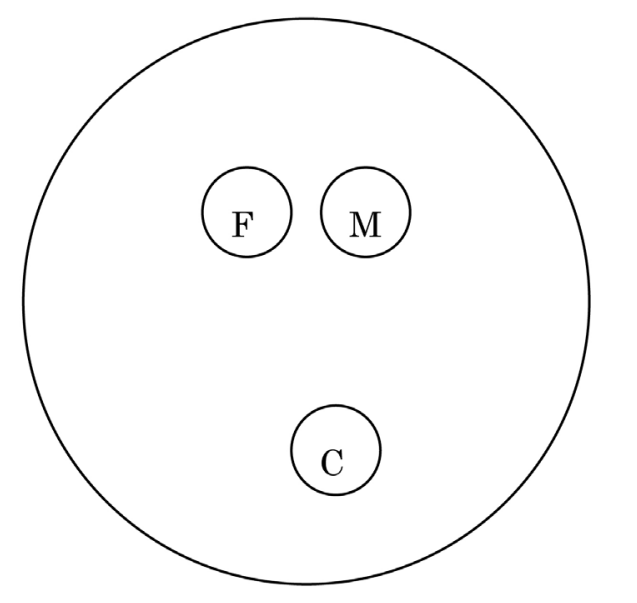

Pattern with a close distance between mother and father

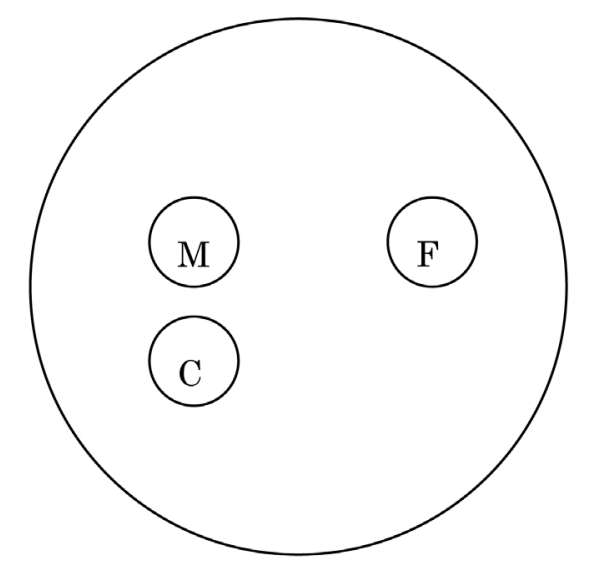

Pattern with a close distance between mother and child

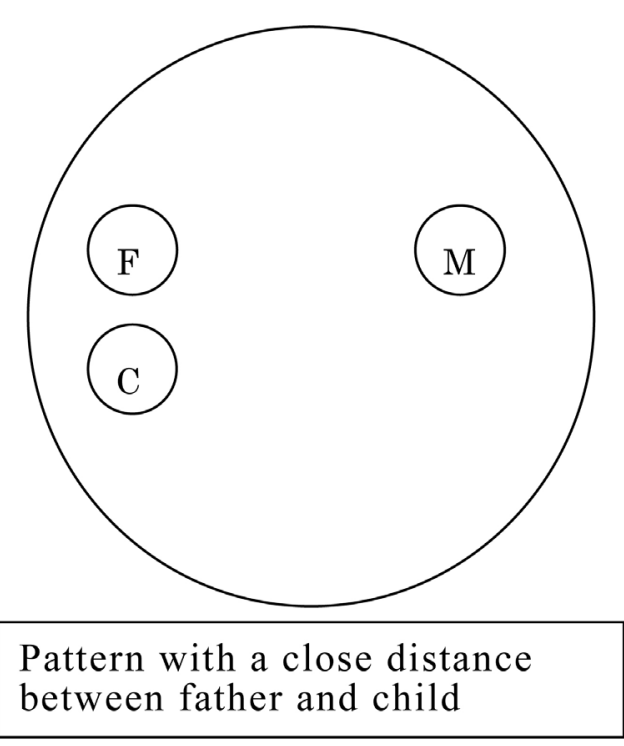



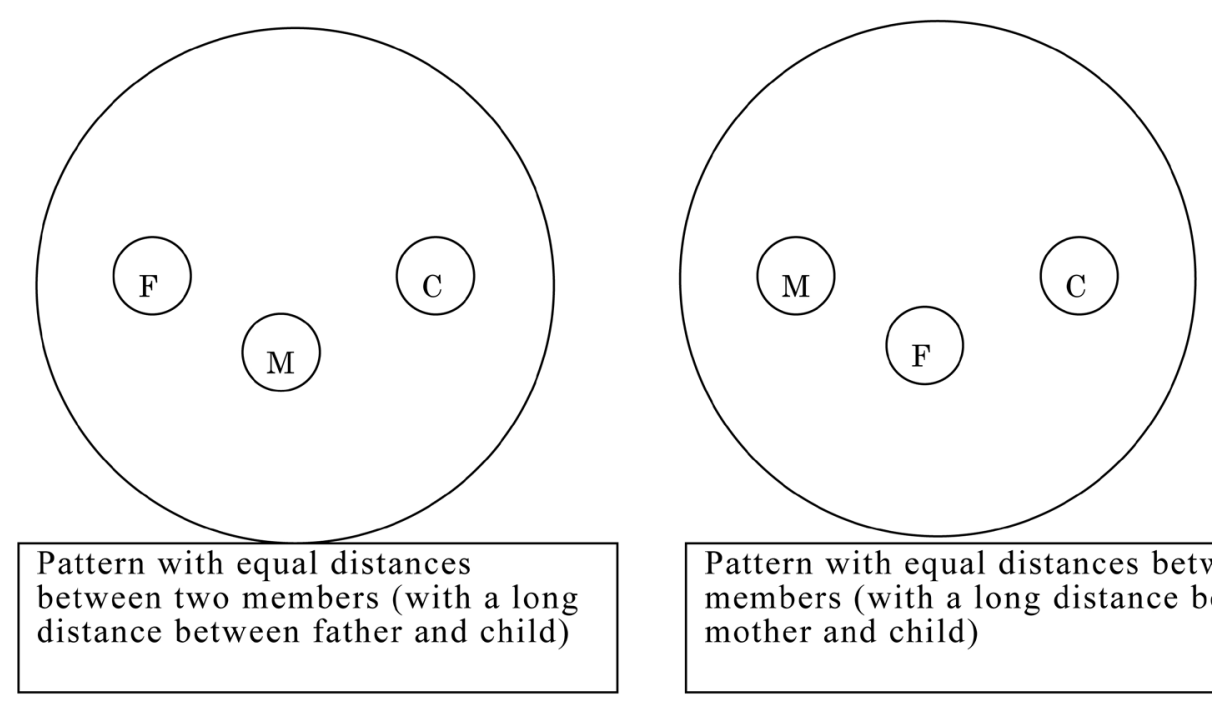

Pattern with equal distances between two members (with a long distance between mother and child)

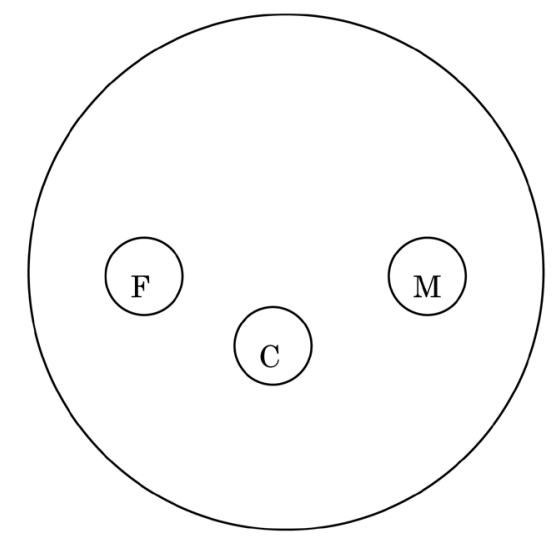

Pattern with equal distances between two members (with a long distance between mother and father)

Figure 1. Categorization of family patterns. F: Father, M: Mother, C: Child.

\section{Results}

\subsection{The Number of Subjects Categorized According to Family Patterns}

154 subjects were associated with the pattern with equal and close distances among the three members (34\%), 70 subjects were associated with the pattern with equal and intermediate distances among the three members (16\%), 10 subjects were associated with the pattern with a close distance between father and child (2\%), 89 subjects were associated with the pattern with a close distance between mother and child (20\%), 59 subjects were associated with the pattern with a close distance between mother and father (13\%), 30 subjects were associated with the pattern with equal and long distances among the three members (7\%), 22 subjects were associated with the pattern with equal distances between two members (with a long distance between father and child) (5\%), 6 subjects were associated with the pattern with equal distances between two members 
(with a long distance between mother and child) (1\%), and 11 subjects were associated with the pattern with equal distances between two members (with a long distance between mother and father) (2\%).

\subsection{The Mental Health Categorized According to Family Patterns} (Table 1)

The average self-esteem score was $21.7 \pm 4.5$. Regarding the average score categorized according to family patterns, the pattern with equal and close distances among the three members was $22.4 \pm 4.2$, the pattern with equal and intermediate distances among the three members was $21.9 \pm 3.9$, the pattern with a close distance between father and child was $20.9 \pm 5.3$, the pattern with a close distance between mother and child was $22.0 \pm 3.3$, the pattern with a close distance between mother and father was $21.9 \pm 4.5$, the pattern with equal and long distances among the three members was $21.9 \pm 3.7$, and the pattern with equal distances between two members was $20.0 \pm 4.5$, respectively. There was no significant difference among the family patterns.

The average self-efficacy score was $26.4 \pm 5.5$. Regarding the average score categorized according to the family patterns, the pattern with equal and close distances among the three members was $26.7 \pm 4.8$, the pattern with equal and intermediate distances among the three members was $26.3 \pm 4.1$, the pattern with a close distance between father and child was $27.0 \pm 3.8$, the pattern with a close distance between mother and child was $28.0 \pm 4.9$, the pattern with a close distance between mother and father was

Table 1 . The mental health categorized according to family patterns.

\begin{tabular}{|c|c|c|c|c|}
\hline & Self-esteem & Self-efficacy & Depression & Anxiety \\
\hline Total average score & $21.7 \pm 4.5$ & $26.4 \pm 5.5$ & $11.9 \pm 5.8$ & $31.9 \pm 8.8$ \\
\hline $\begin{array}{l}\text { Pattern with equal and close } \\
\text { distances among the three } \\
\text { members }\end{array}$ & $22.4 \pm 4.2$ & $26.7 \pm 4.8$ & $11.3 \pm 5.5$ & $31.0 \pm 6.7$ \\
\hline $\begin{array}{l}\text { Pattern with equal and } \\
\text { intermediate distances among } \\
\text { the three members }\end{array}$ & $21.9 \pm 3.9$ & $26.3 \pm 4.1$ & $12.6 \pm 5.8$ & $33.2 \pm 7.2$ \\
\hline $\begin{array}{c}\text { Pattern with equal and long } \\
\text { distances among the three } \\
\text { members }\end{array}$ & $21.9 \pm 3.7$ & $26.0 \pm 5.0$ & $12.1 \pm 4.6$ & $33.3 \pm 8.8$ \\
\hline $\begin{array}{l}\text { Pattern with a close distance } \\
\text { between mother and father }\end{array}$ & $21.9 \pm 4.5$ & $26.4 \pm 5.0$ & $11.6 \pm 5.5$ & $33.8 \pm 9.1$ \\
\hline $\begin{array}{l}\text { Pattern with a close distance } \\
\text { between mother and child }\end{array}$ & $22.0 \pm 3.3$ & $28.0 \pm 4.9$ & $12.2 \pm 5.6$ & $32.7 \pm 7.2$ \\
\hline $\begin{array}{l}\text { Pattern with a close distance } \\
\text { between father and child }\end{array}$ & $20.9 \pm 5.3$ & $27.0 \pm 3.8$ & $15.4 \pm 8.3$ & $32.9 \pm 6.9$ \\
\hline $\begin{array}{l}\text { Pattern with equal distances } \\
\text { between two members }\end{array}$ & $20.0 \pm 4.5$ & $25.6 \pm 4.0$ & $15.0 \pm 5.3$ & $35.5 \pm 9.1$ \\
\hline Significant difference & N.S. & N.S. & $\mathrm{p}<0.01$ & $\mathrm{p}<0.01$ \\
\hline
\end{tabular}


$26.4 \pm 5.0$, the pattern with equal and long distances among the three members was $26.0 \pm 5.0$, and the pattern with equal distances between two members was $25.6 \pm 4.0$, respectively. There was no significant difference among the family patterns.

The average score of the tendency towards depression was $11.9 \pm 5.8$. There were 132 subjects with a score of more than 16 and a tendency towards depression. Regarding the average score categorized according to the family patterns, the pattern with equal and close distances among the three members was $11.3 \pm 5.5$, the pattern with equal and intermediate distances among the three members was $12.6 \pm 5.8$, the pattern with a close distance between father and child was $15.4 \pm 8.3$, the pattern with a close distance between mother and child was $12.2 \pm 5.6$, the pattern with a close distance between mother and father was $11.6 \pm 5.5$, the pattern with equal and long distances among the three members was $12.1 \pm 4.6$, and the pattern with equal distances between two members was $15.0 \pm 5.3$, respectively. There was a significant difference among the family patterns $(\mathrm{p}<0.01)$.

The average score of the tendency towards anxiety was $31.9 \pm 8.8$. There were 34 subjects with a score of more than 45 and a tendency towards anxiety. Regarding the average score categorized according to the family patterns, the pattern with equal and close distances among the three members was $31.0 \pm 6.7$, the pattern with equal and intermediate distances among the three members was $33.2 \pm 7.2$, the pattern with a close distance between father and child was $32.9 \pm 6.9$, the pattern with a close distance between mother and child was $32.7 \pm 7.2$, the pattern with a close distance between mother and father was $33.8 \pm 9.1$, the pattern with equal and long distances among the three members was $33.3 \pm 8.8$, and the pattern with equal distances between two members was $35.5 \pm 9.1$, respectively. There was a significant difference among the family patterns $(\mathrm{p}<0.01)$.

\subsection{The Relationship between the Family Patterns and Gender Differences}

Regarding the number of male subjects categorized according to the family patterns in decreasing order, the pattern with equal and close distances among the three members was 81 subjects (38\%), the pattern with equal and intermediate distances among the three members was 37 (18\%), the pattern with a close distance between mother and father was $31(15 \%)$, the pattern with a close distance between mother and child was 28 (13\%), the pattern with equal distances between two members was 17 (8\%), the pattern with equal and long distances among the three members was $13(6 \%)$, and the pattern with a close distance between father and child was 4 (2\%). Regarding the number of female subjects, the pattern with equal and close distances among the three members was 79 subjects (32\%), the pattern with a close distance between mother and child was $62(26 \%)$, the pattern with equal and intermediate distances among the three members was $36(15 \%)$, the pattern with a close distance between mother and father was 27 (11\%), the pattern with equal distances between two members was $16(7 \%)$, the pattern with equal and long distances among the three members was $16(7 \%)$, and the pattern 
with a close distance between father and child was $4(2 \%)$.

As a common characteristic between genders, the largest was the number of subjects categorized into the pattern with equal and close distances among the three members, while the smallest was the number of subjects categorized into the pattern with a close distance between father and child; in contrast, as a difference between genders, the ratio of female subjects categorized into the pattern with a close distance between mother and child was approximately twice that of male subjects. There were no significant differences between genders in the average scores of each item and no difference in the results categorized according to the family patterns between the overall results and the results categorized by gender (data not shown).

\section{Discussion}

Based on the overall average scores of the degree of self-esteem, it is believed that the pattern with equal and close distances among the three members and the pattern with a close distance between mother and child are categorized into a group with a relatively high degree of self-esteem, the pattern with a close distance between mother and father, the pattern with equal and long distances among the three members, and the pattern with equal and intermediate distances among the three members are categorized into a group with an average degree of self-esteem, and the pattern with a close distance between father and child and the pattern with equal distances between two members are categorized into a group with a relative low degree of self-esteem. Although there were no significant differences in this study, the results showed that those who are satisfied with the relationship with their parents have a lower degree of self-esteem, while those who are dissatisfied with the relationship with their parents have a higher degree of self-esteem. Moreover, based on the overall average scores of the degree of self-efficacy, it is believed that the pattern with a close distance between mother and child and the pattern with a close distance between father and child are categorized into a group with a relative high degree of self-efficacy, the pattern with equal and close distances among the three members, the pattern with a close distance between mother and father, the pattern with equal and intermediate distances among the three members, and the pattern with equal and long distances among the three members are categorized into a group with an average degree of self-efficacy, and the pattern with equal distances between two members is categorized into a group with a relatively low degree of selfefficacy. It is believed that one of reasons for these results is that those with a higher degree of self-esteem/self-efficacy demand a higher level of family relationships, resulting in dissatisfaction with the present condition, while those with a lower degree of selfesteem/self-efficacy may make up for the compromise in or lack of confidence in family relationships through relationships with others. Since this study only focused on the psychological distance among family members, it can be assumed that different results might have been obtained if a survey on satisfaction was added.

The average score of all items according to the SAS was $31.9 \pm 8.748$. Regarding the difference in each score of the six types, the tendency towards anxiety was lower in 
children who recognize their family as the pattern with equal and close distances among the three members in comparison with those who recognize their family as the pattern with equal distances between two members. According to the previous study [7], the results showed that the scores regarding the degree of anxiety is higher in the group with unequal distances among the three members (hereinafter, "unbalanced group"), including the pattern with a close distance between father and child/the pattern with a close distance between mother and child/the pattern with a close distance between mother and father/the pattern with equal distances between two members, than the group with equal distances among the three members (hereinafter, "balanced group"), including the pattern with equal and close distances among the three members/the pattern with equal and long distances among the three members/the pattern with equal and intermediate distances among the three members; consequently, it is assumed that the balance in the psychological distance from their parents recognized by children may impact mental health. In this study, the results also showed that the scores regarding the degree of anxiety are higher in the unbalanced group, the pattern with equal distances between two members, than the balanced group, the pattern with equal and close distances among the three members; thus, it can be assumed that balanced psychological distance among family members is better.

Regarding the difference in scores with respect to depression according to the DSRS$\mathrm{C}$ test, the tendency towards depression was lower in children who recognize their family as the pattern with equal and close distances among the three members than those who recognize their family as the pattern with equal distances between two members; in other words, as shown in the results regarding the tendency towards anxiety, the scores regarding depression were higher in the unbalanced group than the balanced group. As expected, it can also be assumed that the recognition of children that their parents treat them just as the mother and father treat each other or that the relationship between parents and children and that between mother and father are equally good lead to a decrease in the depressive state of children.

There was no significant difference between genders regarding the average score of each item. However, this study showed a tendency for higher scores regarding depression in female subjects. Regarding gender differences, the scores of female subjects were similarly higher in adolescents in the study employing DSRS-C [13]. Against this background, the impact of complicated developmental aspects can be considered, including that secondary sex characteristics are exhibited earlier in females, which accelerates the acquisition of sexual role and self-awareness.

In this study, we examined the relationship between the family relationships recognized by children and mental health, with emphasis on the forms of recognition from the viewpoint of children. However, the specific relationship between family relationships and mental health was not revealed. The first reason for this was thought to be an insufficient explanation in the questionnaire sheets. The purpose of this study was to ask the subjects to express the psychological distances among family members; however, due to a lack of emphasis, some answers were expressed in terms of physical dis- 
tance. As the second reason, it can be assumed that there was no significant difference in the analysis results, since the survey was conducted at only one university and focused on university students at the post-secondary education level in a relatively good environment. From this perspective, more realistic results might be obtained if the survey was conducted in a public elementary/secondary school among students with more diverse family backgrounds.

\section{Conclusion}

In this study, although no specific relationship between family relationship and personality formation was revealed, we found some trends to be clues supporting the fact that building family relationships impacts personality formation.

\section{References}

[1] Markus, H. and Kitayama, S. (1991) Culture and the Self: Implications for Cognition, Emotion, and Motivation. Psychological Review, 98, 224-253.

http://dx.doi.org/10.1037/0033-295X.98.2.224

[2] Bandura, A. (1977) Self-Efficacy: Toward a Unifying Theory of Behavioral Change. Psychological Review, 84, 191-215. http://dx.doi.org/10.1037/0033-295X.84.2.191

[3] Omasu, F., Uemura, S. and Yukizane, S. (2015) The Impact of Family Relationships on the Smoking Habits of University Students. Open Journal of Preventive Medicine, 5, 14-22. http://dx.doi.org/10.4236/ojpm.2015.51002

[4] Omasu, F., Ueno, Y., Sakazaki, Y. and Nishimura, Y. (2016) Association between the Way of Being Scolded and Self-Esteem in University Students. Open Journal of Preventive Medicine, 6, 84-95. http://dx.doi.org/10.4236/ojpm.2016.62007

[5] Mizushima, K. (1978) Integrative Approaches to Human Experience and Congnitive World. Annual Report of the Bunkyo University, 12, 1-11. (In Japanese)

[6] Kusada, H. and Yamada, Y. (1998) A Study of Figures of Family Relationships VI: Correlation between the Difference of Perceived Mental Distance by Marital Couples and Their Family Communication. Bulletin of Human Science, 20, 123-127. (In Japanese)

[7] Uchida, T. and Fujimori, T. (2007) A Study on the Connection between Family Relationship and Children's Depression and Fear. Bulletin of Kyoto University of Education, 110, 93-110. (In Japanese)

[8] Kusada, H. (2002) Figures of Family Relationships: The Viewpoint of Family Assessment. Bulletin of Human Science, 24, 5-10. (In Japanese)

[9] Narita, K., Shimonaka, Y., Nakazato, K., Kawaai, C., Sato, S. and Osada, Y. (1995) A Japanese Version of the Generalized Self-Efficacy Scale: Scale Utility from the Life Span Perspective. Japanese Journal of Educational Psychology, 43, 306-314. (In Japanese) http://dx.doi.org/10.5926/jjep1953.43.3_306

[10] Birleson, P. (1981) The Validity of Depressive Disorder in Childhood and the Development of a Self-Rating Scale: A Research Report. Journal of Child Psychology and Psychiatry, 22, 73-88. http://dx.doi.org/10.1111/j.1469-7610.1981.tb00533.x

[11] Birleson, P., Hudson, I., Buchanan, D.G. and Wollf, S. (1987) Clinical Evaluation of a SelfRating Scale for Depressive Disorder in Childhood (Depression Self-Rating Scale). Journal of Child Psychology and Psychiatry, 28, 43-60.

http://dx.doi.org/10.1111/j.1469-7610.1987.tb00651.x 
[12] Zung, W.W.K. (1965) A Self-Rating Depression Scale. Archives of General Psychiatry, 12, 63-70. http://dx.doi.org/10.1001/archpsyc.1965.01720310065008

[13] Denda, K., Kako, Y., Sasaki, Y., Ito, K., Kitagawa, N. and Koyama, T. (2004) Depressive Symptoms in a School Sample of Children and Adolescents; Using the Birleson Depression Self-Rating Scale for Children (DSRS-C). Japanese Journal of Child and Adolescent Psychiatry Supplement, 45, 424-436. (In Japanese)

Submit or recommend next manuscript to SCIRP and we will provide best service for you:

Accepting pre-submission inquiries through Email, Facebook, LinkedIn, Twitter, etc. A wide selection of journals (inclusive of 9 subjects, more than 200 journals)

Providing 24-hour high-quality service

User-friendly online submission system

Fair and swift peer-review system

Efficient typesetting and proofreading procedure

Display of the result of downloads and visits, as well as the number of cited articles

Maximum dissemination of your research work

Submit your manuscript at: http://papersubmission.scirp.org/

Or contact ojpm@scirp.org 